\title{
Effect of benzoic acids on barite and calcite precipitation
}

\author{
Sandra R. Freeman, Franca Jones", Mark I. Ogden, Allan Oliviera, William R. Richmond
}

AJ Parker Co-operative Research Centre for Integrated Hydrometallurgy Solutions, Nanochemistry Research Institute, Curtin University of Technology, GPO Box U1987, Perth WA 6845 Australia.

ABSTRACT. The effect of various benzoic acids on the precipitation of barite and calcite was investigated. The acids varied in the number of carboxylate groups, from di-benzoic acids (phthalic, isophthalic and terephthalic) through to the hexabenzoic acid (mellitic acid). It was found that the stereochemistry of the di-benzoic acids was important, as was the $\mathrm{pH}$ of the solution (trimesic acid was used as a test case and showed greatest inhibition was achieved with all carboxylate groups deprotonated). Interestingly, for both the calcite and barite systems, mellitic acid was found to be both a potent inhibitor and a significant crystal growth modifier. In the case of barite, the presence of mellitic acid produced nanoparticles that agglomerated. The nanoparticles were found to be $\sim 20 \mathrm{~nm}$ in size from XRD linewidth analysis and 20-50nm from TEM. Humic acid was also tested and found to form bundled fibres of barium sulfate.

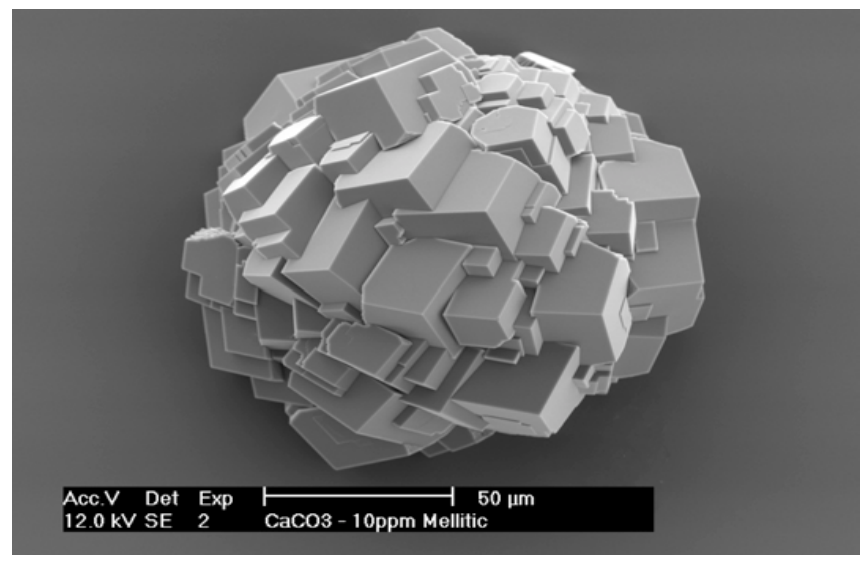

\footnotetext{
*AJ Parker Co-operative Research Centre for Integrated Hydrometallurgy Solutions, Nanochemistry Research Institute, Curtin University of Technology, GPO Box U1987, Perth WA 6845 Australia.

Phone: +61892667677 Fax: +61892664699 email: franca@power.curtin.edu.au
} 


\section{Effect of benzoic acids on barite and calcite}

\section{precipitation}

Sandra R. Freeman, Franca Jones*, Mark I. Ogden, Allan Oliviera, William R. Richmond

$\bowtie *$ AJ Parker Co-operative Research Centre for Integrated Hydrometallurgy Solutions, Nanochemistry Research Institute, Curtin University of Technology, GPO Box U1987, Perth WA 6845 Australia. Phone: +6189266 7677 Fax: +6189266 4699 email:

franca@power.curtin.edu.au

RECEIVED DATE (to be automatically inserted after your manuscript is accepted if required according to the journal that you are submitting your paper to)

TITLE RUNNING HEAD. Effect of benzoic acids on barite and calcite

ABSTRACT. The effect of various benzoic acids on the precipitation of barite and calcite was investigated. The acids varied in the number of carboxylate groups, from di-benzoic acids (phthalic, isophthalic and terephthalic) through to the hexabenzoic acid (mellitic acid). It was found that the stereochemistry of the di-benzoic acids was important, as was the $\mathrm{pH}$ of the solution (trimesic acid was used as a test case and showed greatest inhibition was achieved with all carboxylate groups deprotonated). Interestingly, for both the calcite and barite systems, mellitic acid was found to be both a potent inhibitor and a significant crystal growth modifier. In the case of barite, the presence of mellitic acid produced nanoparticles that agglomerated. The nanoparticles were found to be $\sim 20 \mathrm{~nm}$ in size from XRD linewidth analysis and 20-50nm from TEM. Humic acid was also tested and found to form bundled fibres of barium sulfate. 
KEYWORDS. Barium sulfate, calcium carbonate, benzoic acids, precipitation, nucleation, morphology.

BRIEFS. Effect of benzoic acids on barite and calcite precipitation

\section{MANUSCRIPT TEXT.}

\section{INTRODUCTION}

Barium sulfate is a scale compound commonly encountered during the production of oil from offshore rigs ${ }^{1-3}$. It is also a simple precipitation system often used as a model system ${ }^{4}$. Benzoic acids have also been an area of interest, generally as model compounds for understanding the behaviour of naturally occurring humic substances in the environment ${ }^{5-7}$. The consensus about the role of dissolved humic matter is that it stabilizes ions in solution. This is often assumed to be via a complexing reaction and so the humic matter is affecting the activity of ions in solution ${ }^{8,9}$.

There is a vast amount of previous literature describing the effect of various organics on the precipitation of barium sulfate and calcium carbonate (eg 10-13), however, while carboxylates are well known to be crystal growth modifiers of calcite they are regarded as essentially harmless to barite precipitation $^{14}$. The use of additives in precipitation can be desirable for two reasons. Additives can dramatically affect particle shape and size and therefore can be used in a particle engineering sense, i.e. to obtain the desired physical properties of the particles in question ${ }^{15}$. Additives can also inhibit nucleation and growth and be used as scale inhibitors ${ }^{16}$. However, in order to properly use additives in this way and to intelligently design additives for future use, a fundamental understanding of their behaviour is required.

Recently, we found that an amino carboxylate and a carboxylate-functionalised calixarene molecule were relatively good crystal growth modifiers for both barite and calcite ${ }^{17,18}$. Thus, it appears that the belief that small molecule carboxyates are weak inhibitors is not always borne out. The work with calixarenes lead us to think about other systems that have a rigid backbone but can still have numerous 
functionalities. Thus, the idea of testing the effect of benzoic acids on both calcite and barite precipitation was developed.

We present here, for the first time (as far as the authors are aware), results showing that benzyl carboxylates can be very effective inhibitors of barium sulfate. Additionally, humic acid has been shown to inhibit barite precipitation and its effect is not quite the same as any of the benzoic acids.

\section{EXPERIMENTAL}

The materials used in this study were AR grade, from Ajax Chemicals or BDH and were dissolved to the required concentrations using MilliQ water. Filtered MilliQ water $(0.2 \mu \mathrm{m})$, having a resistivity of $18 \mathrm{M} \Omega \mathrm{cm}$, was used throughout. Organic additives were AR grade from Aldrich. They were: benzene1, 2-dicarboxylic acid (phthalic acid), benzene-1, 3-dicarboxylic acid (isophthalic acid), benzene-1, 4dicarboxylic acid (terephthalic acid), benzene-1, 3, 5-tricarboxylic acid (trimesic acid), benzene-1, 2, 4, 5-tetracarboxylic acid (pyromellitic acid) and benzene-1, 2, 3, 4, 5, 6-hexacarboxylic acid (mellitic acid). Humic acid was obtained from Aldrich and was AR grade.

Schematic diagrams of these molecules (except the humic acid) are shown in Figure 1. The organics were chosen to investigate the effect of different number of functional groups as well as the stereochemistry of the groups. 
1

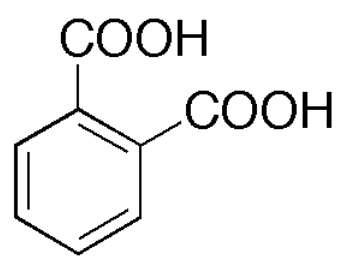

4<smiles>O=C(O)c1cc(C(=O)O)cc(C(=O)O)c1</smiles>

5<smiles>O=C(O)c1cc(C(=O)O)c(C(=O)O)cc1C(=O)O</smiles>

6

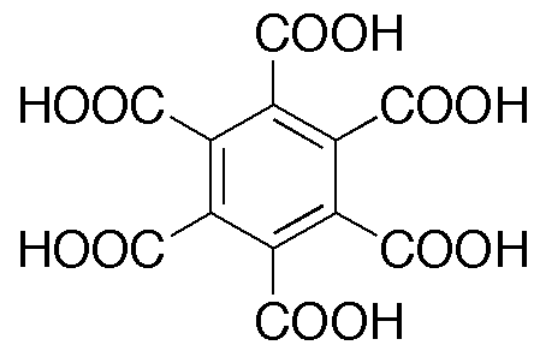

Figure 1. Organic additives investigated in this work: 1. phthalic acid, 2. isophthalic acid, 3. terephthalic acid, 4. trimesic acid, 5. pyromellitic acid, 6. mellitic acid

\section{Conductivity}

Unseeded, de-supersaturation curves were conducted using a cell kept at $25^{\circ} \mathrm{C}$ by a water bath and monitored using conductivity (WTW LF 197 Conductivity meter). An overhead stirrer (150 rpm) was used to keep the solids in suspension. The method of barite precipitation consisted of equilibrating 0.249 $\mathrm{mM} \mathrm{BaCl} 2$ and adding $1 \mathrm{~mol}$ equivalent of $\mathrm{Na}_{2} \mathrm{SO}_{4}$ solution to initiate crystallization as described in a previous publication [19]. The total volume for all experiments was $201 \mathrm{~mL}$. The graph of conductivity versus time was used to calculate $\mathrm{k}_{\mathrm{obs}}$ (observed de-supersaturation rate) by fitting the linear region of the de-supersaturation curve. The $\mathrm{pH}$ for all experiments was 5.6 except where specified. Organic additives were added to the barium chloride solution prior to the addition of sulfate. The desupersaturation rate was found to have an error of $\sim 10 \%$. 
Turbidity experiments were undertaken using a nephelometer probe (Analite NEP 160 from McVan Instruments) with a $90^{\circ}$ detector. For the barite precipitation experiments, the barium chloride concentration, sodium sulfate concentrations and temperature were all equivalent to those used in the conductivity experiments. Only the stirring rate $(300 \mathrm{rpm})$ was altered to ensure sufficient particles were detected. Autonucleated calcium carbonate precipitation was studied under similar conditions using a solution composition of $15 \mathrm{mM} \mathrm{NaHCO}$ and $19 \mathrm{mM} \mathrm{CaCl}_{2}$, with the required additive concentration. The error in this method for the determination of induction time was found to be $\sim 15 \%$.

\section{Calcium Carbonate Crystal Growth}

Calcium carbonate crystals were grown slowly in the presence of additives, by diffusion of carbon dioxide and ammonia into a calcium chloride solution, as described previously ${ }^{17}$. The crystal morphology was examined in the scanning electron microscope.

\section{SEM and TEM}

For the barium sulfate runs, samples were collected by filtration onto $0.22 \mu \mathrm{m}$ membranes. After washing and drying in a desiccator, a portion of the filter paper was placed onto carbon coated stubs and stored in a desiccator. The samples were gold sputtered prior to viewing in a Philips XL30 SEM. For those runs that did not precipitate in the time frame of the experiment $(\sim 3$ hours $)$, particles were collected after 3 days. In the case of mellitic acid, a $5 \mathrm{~L}$ batch was prepared in order to collect sufficient solids. After washing and drying the solids in an oven at $55^{\circ} \mathrm{C}$, the particles were set in resin and thin sections prepared by ultramicrotomy. Transmission Electron Microscopy (TEM) of ultramicrotomed samples was carried out in a JEOL 2011 transmission electron microscope operated at 200kV.

\section{$X R D$}

Powder XRD patterns were collected on solids obtained from $5 \mathrm{~L}$ batch repeat experiments scaled up from the conductivity runs. Patterns were recorded on a Siemens D500 Powder Diffractometer using $\mathrm{Cu}-\mathrm{Ka}$ radiation $(30 \mathrm{~mA}, 40 \mathrm{kV})$. Samples were step scanned from $5^{\circ}$ to $90^{\circ} 2 \mathrm{q}$, at $0.02^{\circ}$ increments, using a counting time of 6 seconds per increment. Average crystallite sizes were calculated using the Scherrer equation. Crystallite sizes were determined as an average of three values obtained from the 
linewidths at half maximum measured on the 211, 112 and 020 diffraction lines in the barite XRD pattern.

\section{RESULTS}

Di-benzoic acids and the effect of stereochemistry.

There are three different di-benzoic acids; phthalic acid (1 in Figure 1), isophthalic acid (2 in Figure 1) and terephthalic acid (3 in Figure 1). These three substances were used to test whether it was important where the carboxylic acids were situated on the benzene ring for inhibition of barium sulfate precipitation.
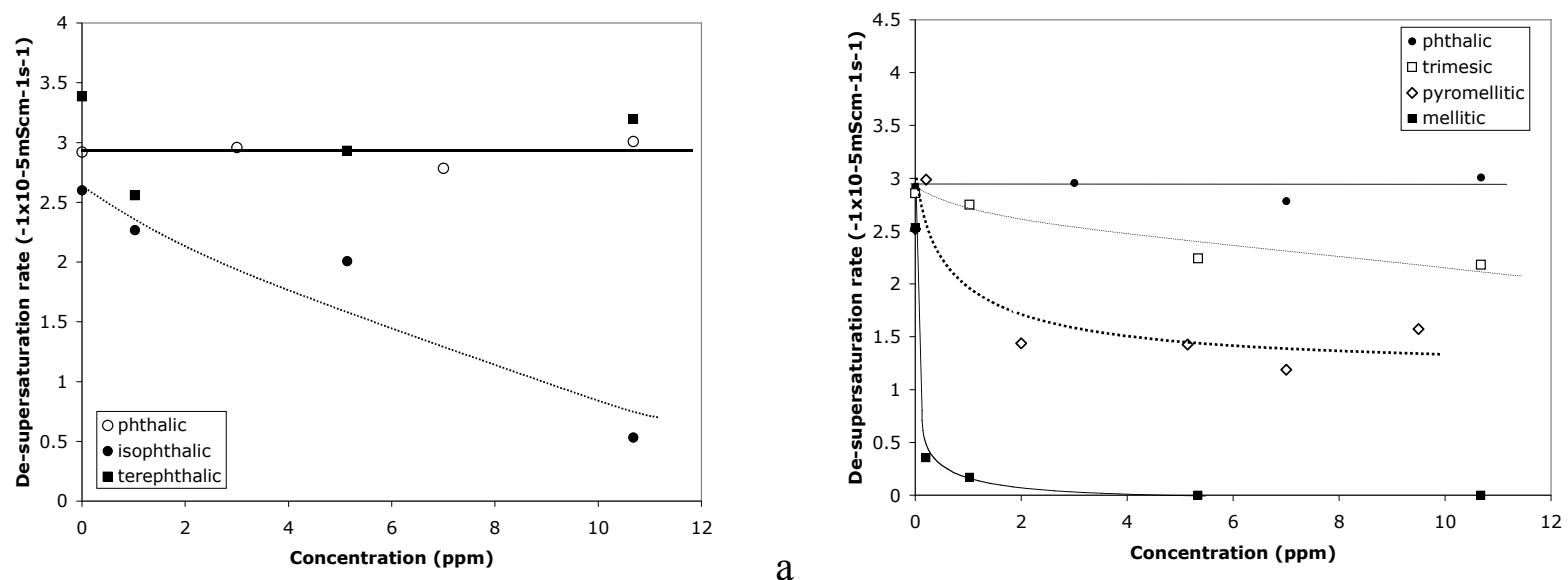

b

Figure 2. De-supersaturation curves versus organic acid concentration for the various benzoic acids tested. a) di-benzoic acids (open circles - phthalic acid, filled circles - isophthalic acid, filled squares - terepthalic acid) b) tri-, tetra- and hexa-benzoic acid (filled circles phthalic acid, open circles - pyromellitic acid, filled squares - mellitic acid, open squares - trimesic acid). Lines drawn to aid reader only.

The 1,3 position (isophthalic acid) appears to be important for the di-benzoic acids as the 1,2 (phthalic acid) and the 1,4 (terephthalic acid) acids appear to have little effect on the precipitation kinetics (Figure 2A). However, the morphology shows a different correlation (Figure 3). The isophthalic acid had only a 
mild effect on the morphology of the resultant barite particles. As can be seen in Figure 3c, the particle's aspect ratio is smaller than those of the control barium sulfate particles. On the other hand, the sample treated with terephthalic acid contained a combination of particle morphologies (Figure 3d), some of which were indistinguishable from the control barite particles while others were very rounded agglomerates.

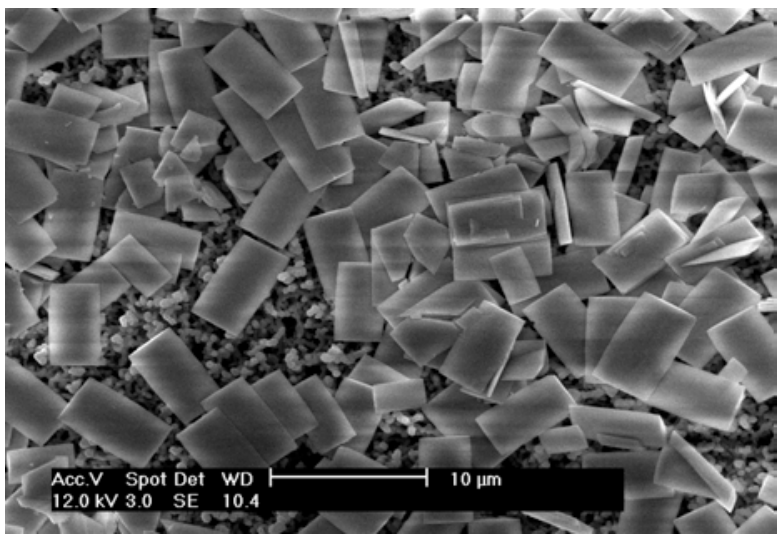

a)

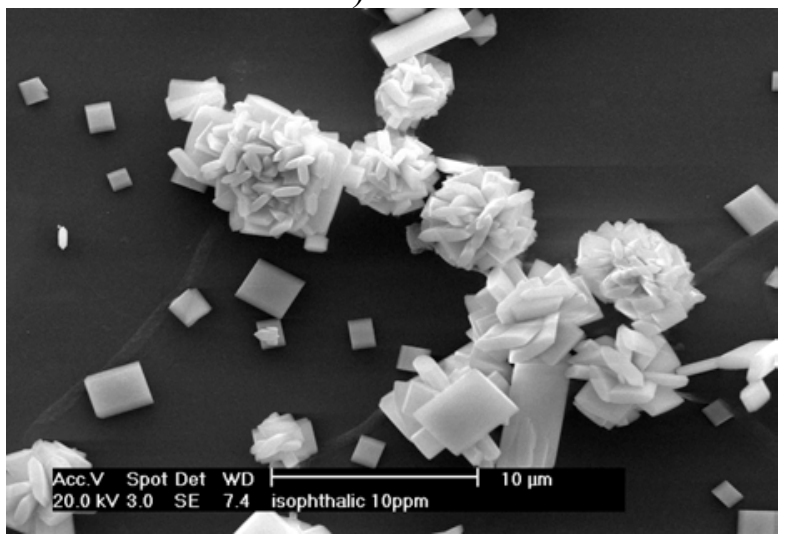

c)

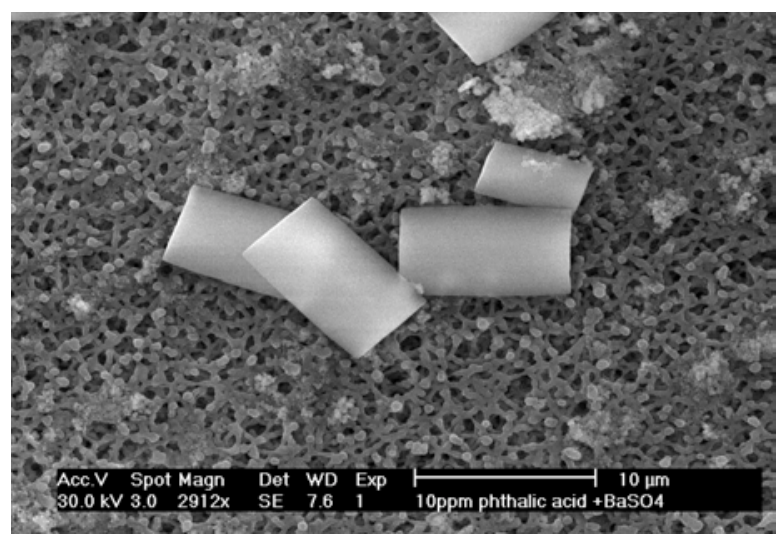

b)

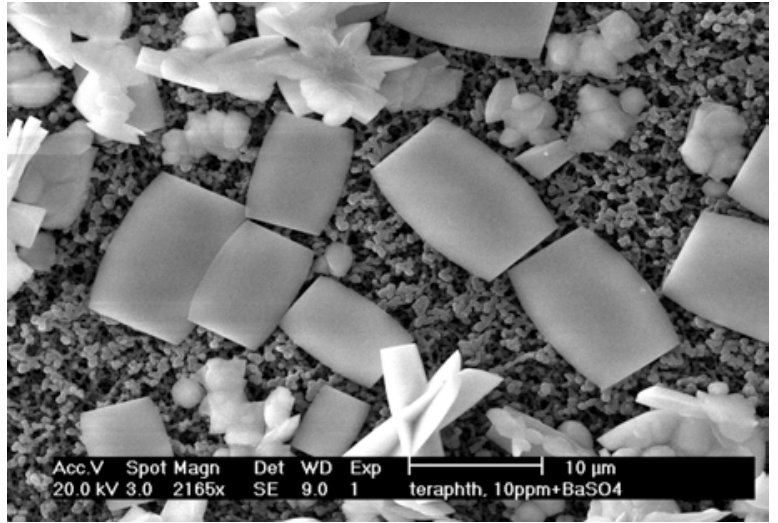

d)

Figure 3. Scanning electron micrographs of barium sulfate particles obtained during conductivity experiments a) control b) phthalic acid present c) isophthalic acid present d) terephthalic acid present (all investigated at $10 \mathrm{ppm} \equiv 0.06 \mathrm{mM}$, porous background in some figures is due to filter paper)

Comparison with the calcium carbonate system showed comparable trends. The three additives had no significant impact on the morphology of calcite produced in slow crystal growth experiments (Fig Supp 1), indicating a minimal influence on the growth of calcite. The impact on nucleation was noteworthy, 
however, with the isophthalic acid displaying the strongest inhibition (Figure 4). Terephthalic acid did not reduce the induction period in comparison to the blank system (less than $100 \mathrm{~s}$ ), and the phthalic acid had an intermediate effect.

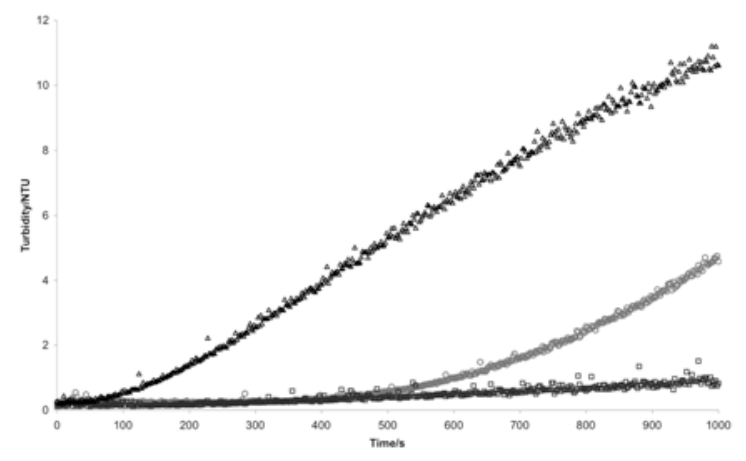

Figure 4. Light scattering as a function of time for supersaturated calcium solutions in the presence of $10 \mathrm{ppm}(0.06 \mathrm{mM})$ of phthalic acid (circles), isophthalic acid (squares) and terephthalic acid (triangles)

\section{Effect of number of acid groups}

The interesting result here was the lack of significant inhibition (Figure 2B) of barium sulfate precipitation found in the presence of trimesic acid despite it having a possible 1,3 adsorption motif (see Figure 1). Not only was inhibition poor but also very little effect on morphology is observed (Figure 5). This was confirmed by the similarity in line-widths from XRD for barite particles from the trimesic and control samples. Thus, no effect on barium sulfate by the presence of trimesic acid is observed (in either size, morphology or inhibition). However, both the pyromellitic and the mellitic acid showed strong inhibition. Overall, the series showed that as the number of carboxylate groups increases, the effect on precipitation inhibition also increases. However, if we include isophthalic acid in our comparison, we find that isophthalic acid is more potent than both the trimesic and pyromellitic acids at the highest concentration. What is clear is that the pyromellitic and mellitic acids inhibit to a greater degree at lower 
concentrations while the isophthalic acid is slower to reach those levels of inhibition. The mellitic acid, which showed the greatest degree of barite precipitation inhibition, had a profound effect on the resultant particle size and morphology. XRD line widths showed a crystallite size of $\sim 20 \mathrm{~nm}$ while SEM showed a particle size of $\sim 500 \mathrm{~nm}$ radius. To confirm that these particles were agglomerates of nanoparticles, ultramicrotomed samples were prepared and viewed by TEM.

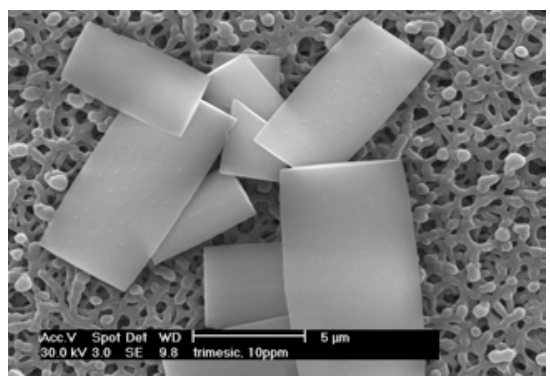

a

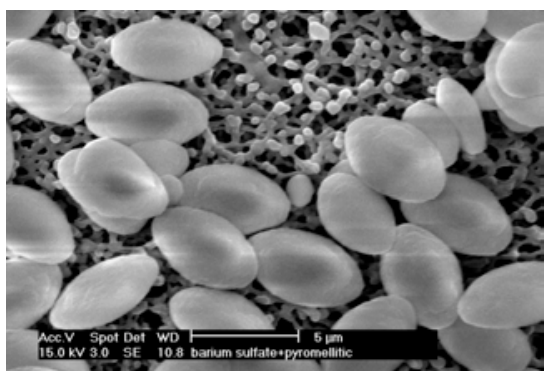

b

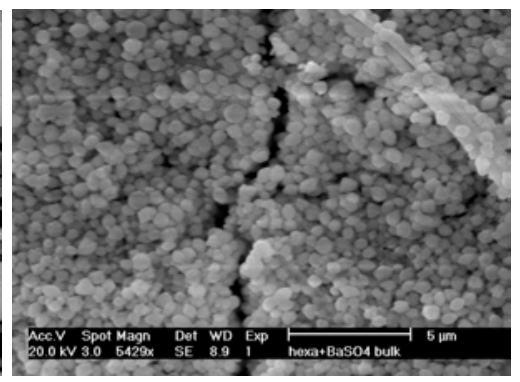

c

Figure 5. Scanning electron micrographs of barite particles formed in the presence of a) $0.05 \mathrm{mM}$ trimesic acid, b) $0.04 \mathrm{mM}$ pyromellitc acid and c) $0.03 \mathrm{mM}$ mellitic acid (all 10ppm equivalent, porous background is due to filter paper)

When prepared as ultra-thin sections for TEM analysis, particles were found to be rather fragile and appeared to be broken up by the ultramicrotomy process (see Figure 6a). What is clear is that these particles are definitely aggregates of nanoparticles. A high magnification image of an intact aggregate shows the primary particles to be of the order of $20-50 \mathrm{~nm}$ in diameter; consistent with the XRD results. Also consistent with this conclusion was the appearance of rings of spots for the Selected Area Electron Diffraction (SAED) pattern from the intact aggregate. 


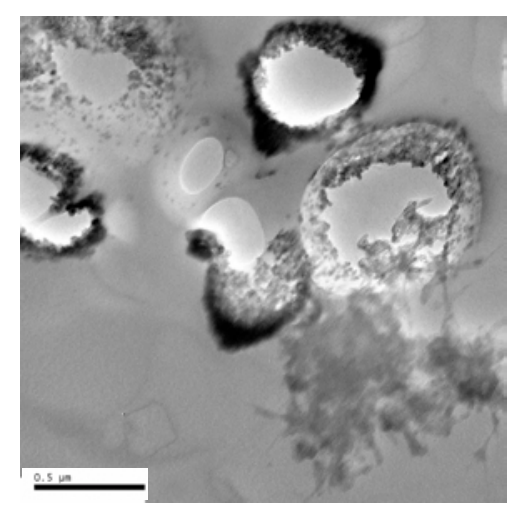

a

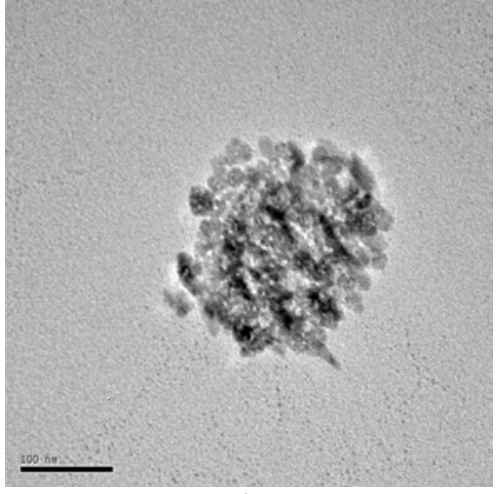

b

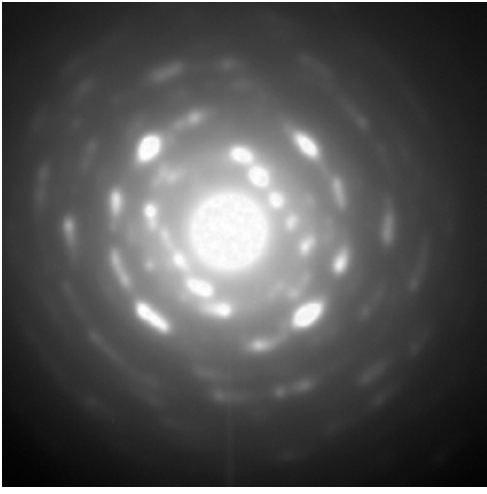

c

Figure 6. Barium sulfate particles viewed after ultramicrotomy by TEM a) low magnification image showing fragile nature of the aggregates formed in the presence of mellitic acid, b) intact aggregate and c) SAED of intact aggregate shown in b)

Again, comparable behaviour was found in the calcium carbonate system, with mellitic acid being the most potent inhibitor, inducing a significant change in morphology (Figure 7), and a dramatically extended induction period in nucleation experiments (from $100 \mathrm{~s}$ in the blank to $2400 \mathrm{~s}$ in the presence of $0.03 \mathrm{mM}$ mellitic acid). Neither trimesic acid, nor pyromellitic acid induced notable changes in crystal morphology or induction period.

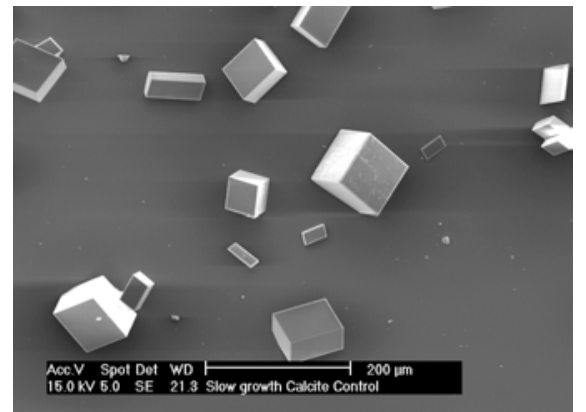

a

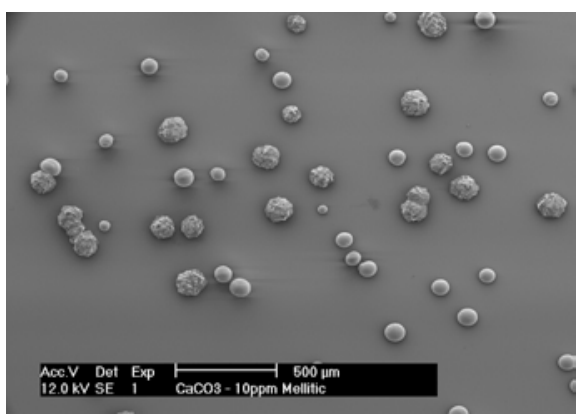

b 


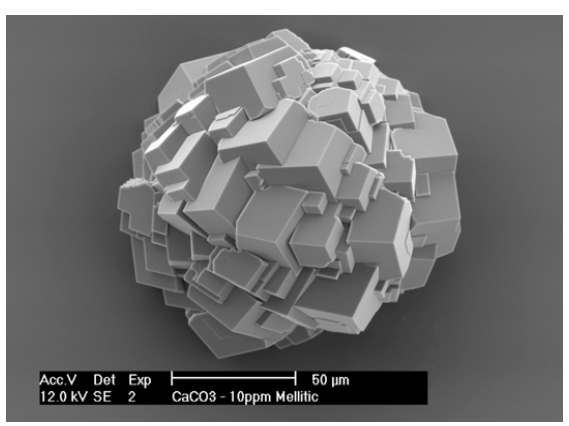

$\mathrm{c}$

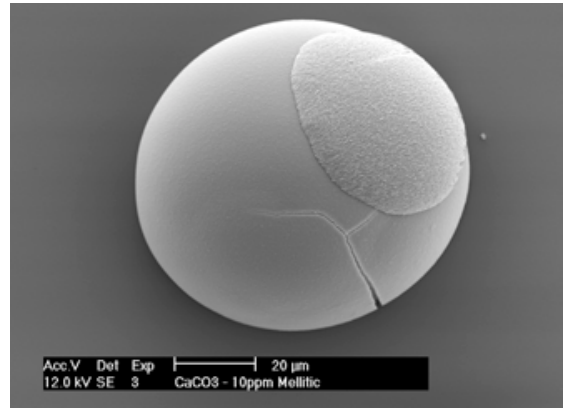

d

Figure 7. Scanning electron micrographs of calcium carbonate crystals grown in the presence of 10 ppm $(0.03 \mathrm{mM})$ mellitic acid (a) blank (b) low magnification showing clusters of calcite and spherical vaterite (c) calcite cluster (d) spherical vaterite

\section{Effect of $p H$}

The effect of $\mathrm{pH}$ was investigated on the trimesic acid molecule, since previous work suggested that inhibition of barite precipitation improved with the functional groups becoming more negative. The desupersaturation rate at each $\mathrm{pH}$ level for barium sulfate was obtained and the ratio taken of the desupersaturation rate with trimesic acid present. Thus, a value of 1 represents no inhibition while a value of 0 represents complete inhibition. It found that, generally, inhibition was improved as $\mathrm{pH}$ increased, although at the highest $\mathrm{pH}(\mathrm{pH} 11)$ it was less effective (Figure 8a). This trend has also been noted for phosphonate $^{20}$ and is in part due to charge screening. It was noted that, at $\mathrm{pH} 11$, the conductivity value was lower in the presence of trimesic acid than the control (unlike all the previous experiments where the reverse was found). Because conductivity measures the mobility of ions in solution, complexation reactions can be sometimes observed by a decrease in conductivity (since the complex has a lower ionic charge normally and therefore a lower mobility). This suggests that at the highest $\mathrm{pH}$ investigated, complexation of the trimesic acid molecule with barium ions might be occurring. This is possible because complexation is preferred at higher $\mathrm{pH}$ due to the higher concentration of fully deprotonated acid.

The nephelometry results show that at $\mathrm{pH} 5$ (Figure 8b), the trimesic acid has very little effect on nucleation rate, thus, its main impact should be on growth. This correlates well with the conductivity 
data and the lack of impact on morphology, though the impact on growth in terms of particle size is not discernable in the SEM pictures.
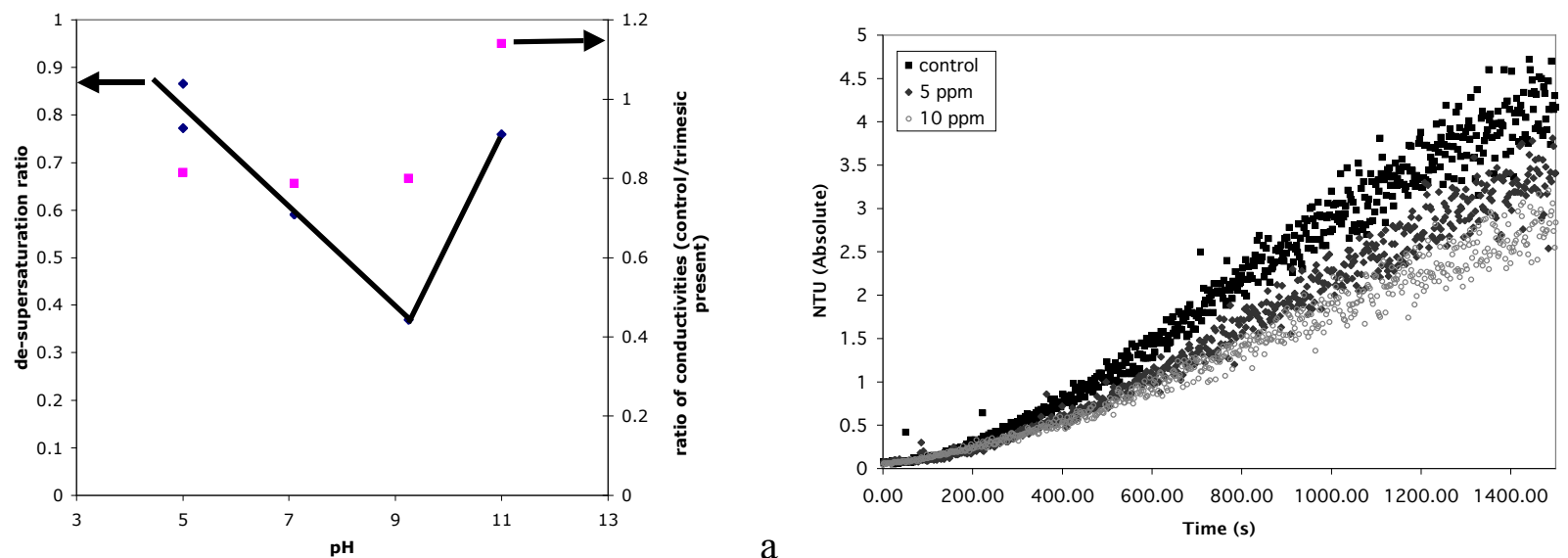

Figure 8. a) De-supersaturation rate of barite precipitation in the presence of $10 \mathrm{ppm}(0.05 \mathrm{mM})$ trimesic acid ratio-ed to the control run at that $\mathrm{pH}$ versus $\mathrm{pH}$ and the ratio of the conductivity value in the presence of trimesic acid to the control value versus $\mathrm{pH} \mathrm{b}$ ) Turbidity of precipitating barite solution in the presence of variable concentrations of trimesic acid at $\mathrm{pH} 5$ (filled squares - no trimesic acid present, filled circles $-0.025 \mathrm{mM}$ trimesic acid present, open circles $-0.05 \mathrm{mM}$ trimesic acid present)

The particles obtained in the presence of trimesic acid at $\mathrm{pH} 5$ and 11 are shown in Figure 9. At all pHs investigated we see very little change between the control (at a given $\mathrm{pH}$ ) and those obtained with trimesic acid present. Only at pH 11 was a combination of particle morphologies observed. In Figure 9d, rectangular particles similar to the control are found, however, the arrow indicates a more rhombohedral particle is also present. Viewing of larger sections showed that indeed the sample consisted of two types of particles: particles with the control morphology and particles with the rhombohedral morphology normally associated with lower supersaturation ratios $^{21}$. This also supports the notion that complexation is occurring, leading to a lower supersaturation (and therefore, rhombohedral particles). 


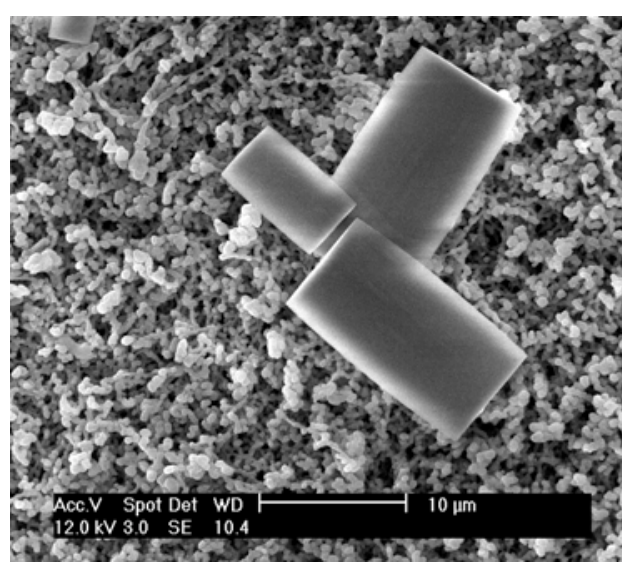

a

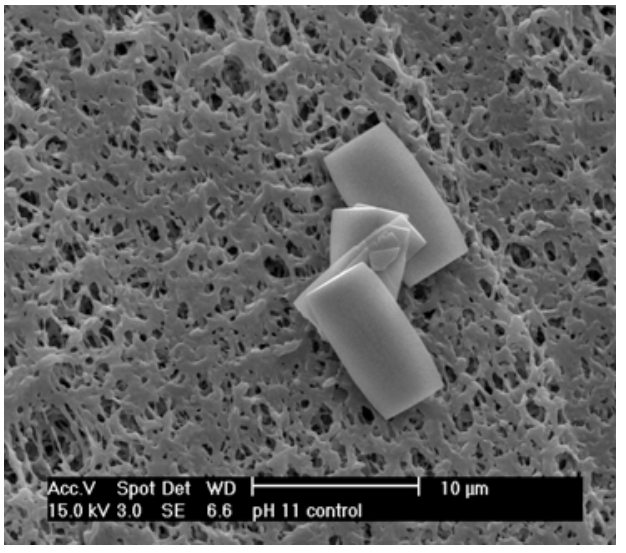

c

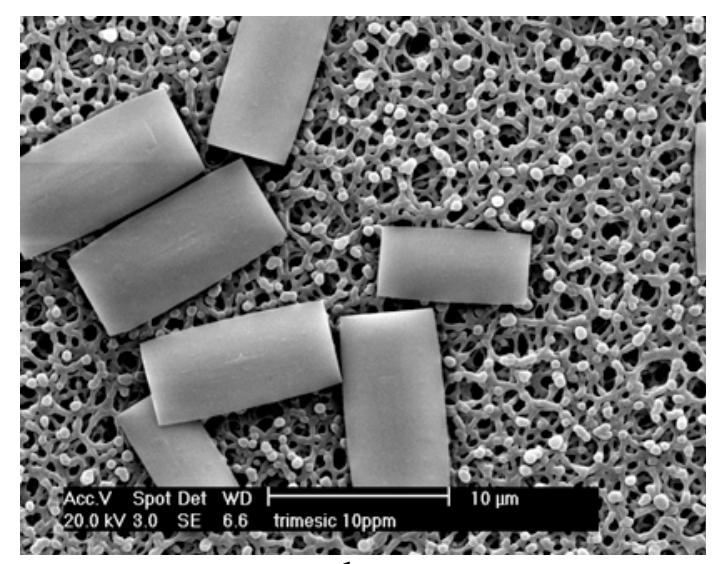

$\mathrm{b}$

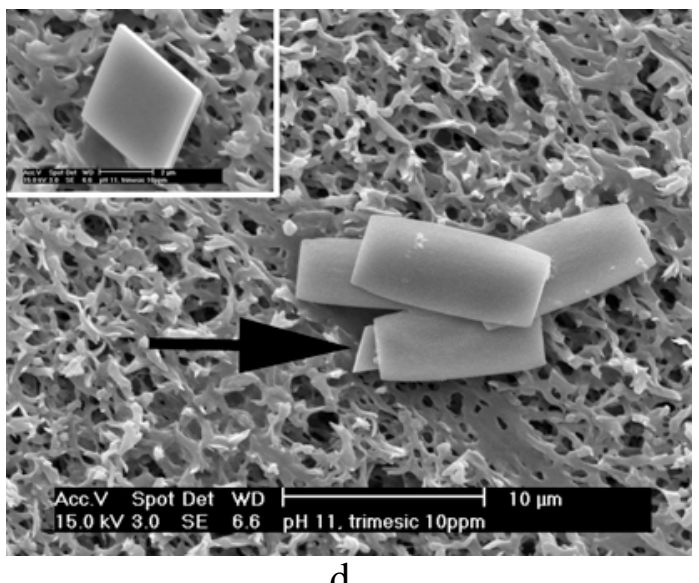

d

Figure 9. Scanning electron micrographs of barium sulfate showing the effect of $\mathrm{pH}$ on barite particle morphology (porous background is due to filter paper) a) $\mathrm{pH} 5$ control b) $\mathrm{pH} 5$ with 10ppm trimesic acid present c) pH 11 control d) pH 11 with 10ppm trimesic acid present showing rectangular particles, the arrow points to a rhombohedral particle lying underneath the other particles, the inset shows a rhombohedral particle from another section of the sample (10ppm is equivalent to $0.05 \mathrm{mM})$

\section{Effect of humic acid}

Humic acid was investigated since it is known to contain many acidic functionalities as well as containing aromatic rings. In fact, the various benzoic acids have been used as model systems for humic acids in the past $^{5-7}$. It was interesting then to find that humic acid had inhibitory powers in-between the mellitic and pyromellitic acids (Figure 10). Even more interesting was the presence of fibre-like barite particles often found with phosphonate polymers ${ }^{22}$ or small phosphonate molecules ${ }^{23}$ like EDTP (EDTP 
$=$ ethylenediaminetetramethylenephosphonic acid). The morphology change observed is not one that can be reproduced by simply altering supersaturation. The inhibitory power of humic acid was not the same as any of the benzoic acids and the morphology change in the presence of humic acid was not reproduced by any of the other benzoic acids. In this respect then, it is perhaps unwise to use benzoic acids as models for humic matter. Recent molecular modelling ${ }^{24}$ on EDTP found a strong interaction with the (100), (210) and (001) faces and previous TEM studies ${ }^{22}$ have shown the fibres to be selfassembled aggregates of nanoparticles elongated in the (001) zone. This suggests that humic acids too have the same strong interaction with these faces (in particular, the (001) and (210) faces). XRD confirmed that the crystallite size was in the nanometer range $(20-30 \mathrm{~nm})$. These results thus suggest that humic acids may not always affect the solution speciation via complexation of ions in solution but can adsorb onto and directly interact with surfaces. However, it does confirm the current wisdom that dissolved humic matter inhibits precipitation.

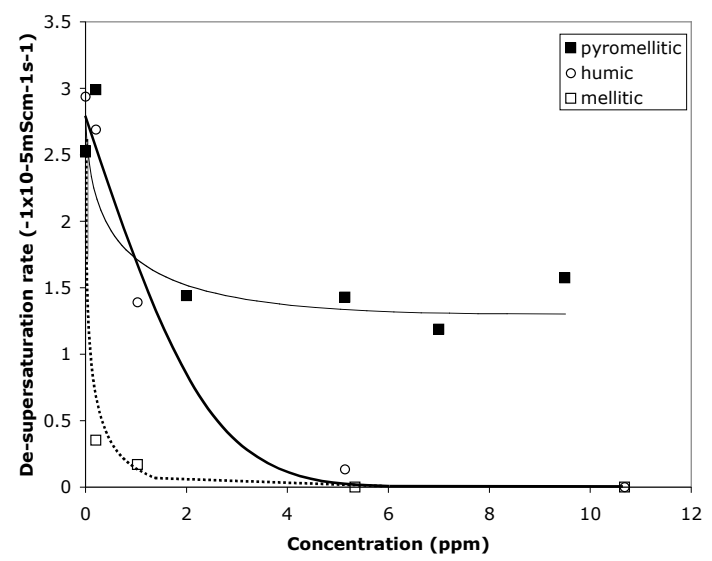

a

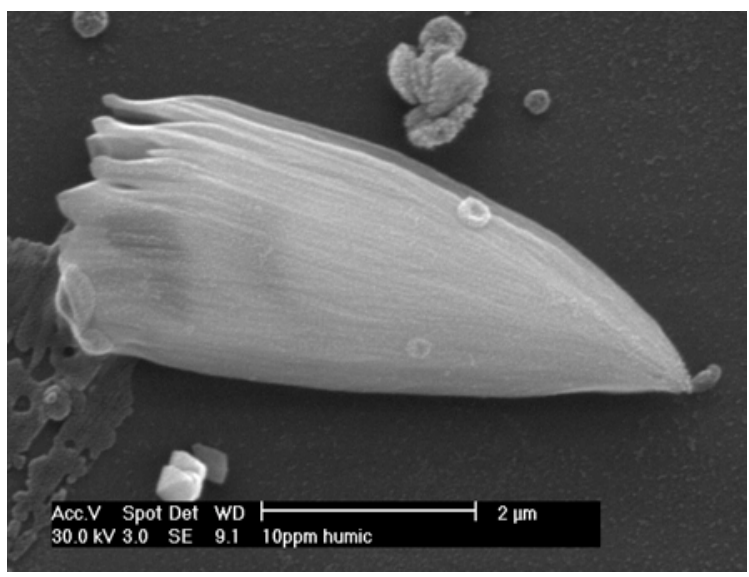

b

Figure 10. a) Comparison of de-supersaturation rate of barite with varying humic acid concentration with barite precipitation in the presence of pyromellitic and mellitic acids (filled squares - pyromellitic acid, open circles - humic acid, open squares - mellitic acid). Lines drawn to aid reader only. b) Scanning electron micrographs of fibre-like particles of barite formed in the presence of humic acid at $10 \mathrm{ppm}$ 


\section{DISCUSSION}

In order to properly assess the impact of the various acids on the precipitation of calcite and barite the pKa values of the acids ${ }^{25}$ were obtained to see whether there was any correlation with the ionisation state and the degree of inhibition observed.

Table 1. $\quad \mathrm{pKa}$ values ${ }^{25}$ for the organic acids investigated

\begin{tabular}{|c|c|c|c|c|c|c|}
\hline Additive & $\mathrm{pKa} 1$ & $\mathrm{pKa} 2$ & $\mathrm{pKa} 3$ & $\mathrm{pKa} 4$ & $\mathrm{pKa} 5$ & $\mathrm{pKa} 6$ \\
\hline phthalic & 2.9 & 5.5 & & & & \\
\hline isopthalic & 3.5 & 4.6 & & & & \\
\hline terephthalic & 3.5 & 4.8 & & & & \\
\hline trimesic & 3.2 & 3.9 & 4.9 & & & \\
\hline pyromellitic & 2.4 & 3.1 & 4.4 & 5.6 & & \\
\hline mellitic & 2.1 & 2.5 & 3.2 & 4.4 & 5.5 & 6.6 \\
\hline
\end{tabular}

Let us concentrate on the di-carboxylates first. From the values shown in Table 1 it becomes clear that the second proton on phthalic acid will not be completely removed at $\sim \mathrm{pH} 5$. So its protonation state may provide a possible reason for its poor performance as an inhibitor. With only one carboxylate group de-protonated, a direct comparison of phthalic acid with the other di-carboxylates is flawed, since one 
molecule contains only one effective carboxylate group while the others have two; both tera- and isophthalic acids would be doubly de-protonated at $\mathrm{pH} 5$.

In the case of trimesic acid, it appears that this molecule should be completely de-protonated by $\mathrm{pH} 5$, but only just. Thus, increases in the $\mathrm{pH}$ will cause an increase in the number of fully de-protonated trimesic acid molecules, which in turn leads to greater efficacy of inhibition. Thus, the observed behaviour of trimesic acid with changes in $\mathrm{pH}$ is as would be expected based on the ionisation state of the molecule. Both the pyromellitic and the mellitic acids are not fully de-protonated at $\mathrm{pH} 5$ but have at least 3 carboxylate groups de-protonated. Thus, we can conclude that inhibition of precipitation is not related to the inhibitor's protonation state alone.

The most intriguing result from this work is the strong inhibition seen in the presence of isophthalic and mellitic acids. Clearly, the number of ionised carboxylic acid functional groups is a significant parameter affecting the degree of barite inhibition. However, the isophthalic acid is more potent as an inhibitor than the trimesic and pyromellitic acid molecules, both of which have equal or greater number of carboxylate groups present, even when ionisation is taken into consideration. In this case, some sort of stereochemical constraint must be altering the adsorption geometry such that precipitation inhibition is weakened for the pyromellitic and trimesic acids.

While the planar nature of both the benzene ring and the carboxylic acid functional group make these molecules good candidates for molecular modelling studies, detailed studies were beyond the scope of this work. The possibility of lattice matching however, was assessed by measuring the oxygen-tooxygen and carbon-to-carbon atom distances for the organic acids from known calcium crystal structures ${ }^{26}$ and comparing these to the barite and calcite anion distances. It must be noted that, due to there being at least four oxygen atoms present, there is a minimum and a maximum O-O distance and intermediate distances are possible even for the di-carboxylic acids. This is shown diagrammatically in Schematic 1. 


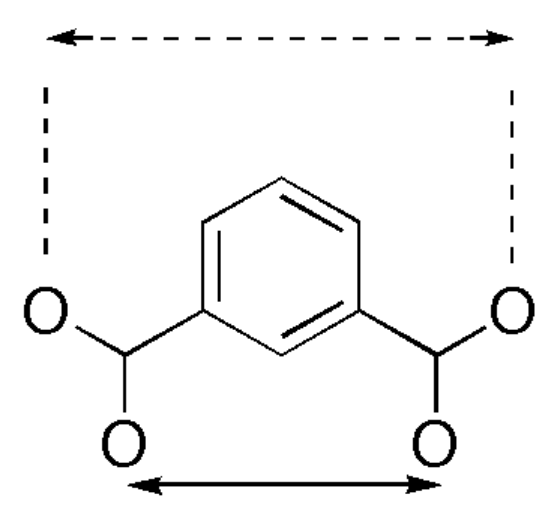

Schematic 1. Schematic showing isophthalic acid. The solid double-headed arrow represents the shortest O-O distance while the dashed double-headed arrow represents the longest O-O distance. Intermediate distances also exist.

Literature suggests that while conformational changes of the organic can be significant ${ }^{24,27}$, if lattice matching does occur, these distance relationships are important.

Table 2. Atomic distances $(\AA)$ in the various organic acids as determined from known crystal structures

\begin{tabular}{|l|c|c|c|c|}
\hline & $\begin{array}{c}\text { Minimum } \\
\text { O-O distance }\end{array}$ & $\begin{array}{c}\text { Maximum } \\
\text { O-O distance }\end{array}$ & $\begin{array}{c}\text { Minimum } \\
\text { C-C distance }\end{array}$ & $\begin{array}{c}\text { Maximum } \\
\text { C-C distance }\end{array}$ \\
\hline Phthalic & 3.004 & 4.807 & 2.910 & NA \\
\hline Isophthalic & 4.921 & 7.203 & 5.020 & NA \\
\hline Terephthalic & 7.007 & 7.355 & 5.800 & NA \\
\hline Trimesic & 5.048 & 7.087 & 5.020 & NA \\
\hline Pyromellitic & 2.997 & 7.374 & 2.998 & 5.816 \\
\hline Mellitic & 3.029 & 7.387 & 2.900 & 5.850 \\
\hline
\end{tabular}

Assuming that the acid groups that adsorb are de-protonated, for lattice matching to occur they must correspond to sulfate/carbonate positions on the barite/calcite faces. The sulfate distances in barite are: $5.77 \AA$ on the (011) face, $5.47 \AA$ (on the (100), (001) and (101) faces), $5.09 \AA$ on the (211) face, $4.63 \AA$ on the (010) face and 4.32-4.39 $\AA$ on the (210) and second cut of the (100) face ${ }^{26}$. For calcite, the 
carbonate distances are equivalent on the exposed faces (as the faces are all (1 $\overline{140})$ ) and are those found on the cleavage plane ${ }^{27}$; namely the carbonate distances are 4.06, 4.80 and $6.27 \AA$.

Given that the distances between surface carbonate and sulfate sites are given as C-C or S-S distances, it is important to check the C-C distance in the benzoic acid to see if there is any match. The phthalic acid is not at all equivalent to any sulfate or carbonate distances. Thus, the lack of effect for phthalic acid can be explained by the lack of lattice matching. This is further supported when it is noted that the calcite experiments were run at a $\mathrm{pH}$ where the phthalic acid should have been fully deprotonated $(>\mathrm{pH} 8)$. The isophthalic acid can probably adsorb into both $5.09 \AA$ spaces of sulfate on barite and the $4.8 \AA$ carbonate distance of calcite ( $\sim \%$ mismatch) and this could explain its potency. The terephthalic acid only matches one of the barite sulfate distances (that for the (011) face) and this could be the reason why we see a morphology effect in the presence of terephthalic acid. It does not explain however, why we do not see an inhibiting effect for barium sulfate precipitation in the presence of terephthalic acid.

As the number of carboxylate groups increases the number of sulfate distances that can be matched increases too. However, an explanation as to why the isophthalic acid is a more potent inhibitor than trimesic acid or pyromellitic acid requires us to consider to the following two possibilities.

i) It is clear that there are two modes in which the organic acids might adsorb: either with the benzene ring co-planar to the surface or at some angle more 'orthogonal' to it (see Schematic 2 below).

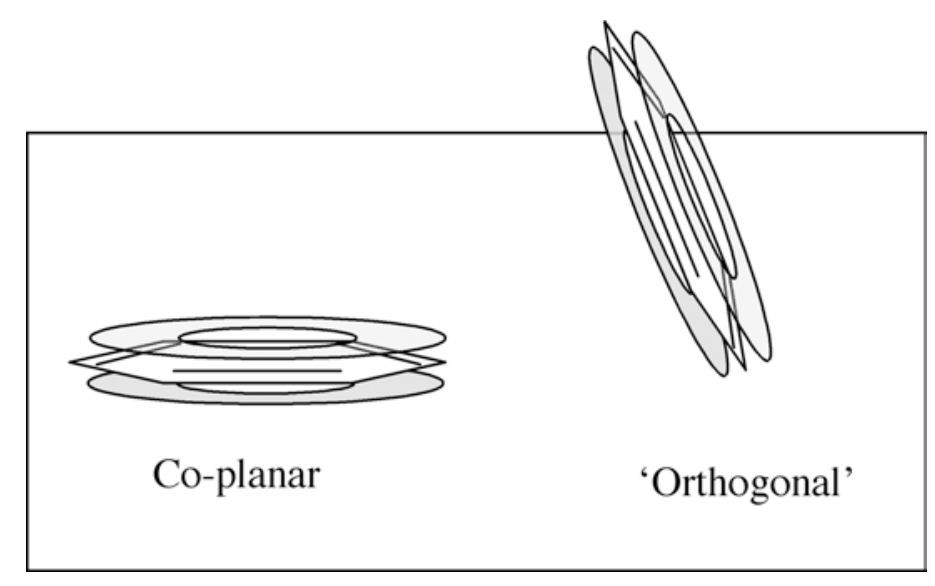


Schematic 2. The benzene ring in the benzoic acids may adsorb either in a planar orientation to the surface or a more upright/orthogonal one

It is possible that one of these positions (co-planar or 'orthogonal') may be more potent than the other with respect to inhibiting crystallization. Infrared results from Nagayasu et al. ${ }^{28}$ suggest that phthalic acid adsorbs onto stainless steel almost perpendicularly but that the trimesic and mellitic acids adsorb at a more inclined angle - closer to the co-planar arrangement. The terephthalic acid would either have to adsorb in a co-planar arrangement or, if in an orthogonal arrangement, adsorb through only one carboxylic acid moiety, and this may explain why it is not a good inhibitor. In any event we plan to undertake molecular modelling studies of these compounds in an effort to elucidate their mode of interaction.

ii) If the molecule is adsorbed in a perpendicular fashion with one or more carboxylate groups 'tethered' to the surface and one or more carboxylate groups directed out towards the solution, the carboxylate group directed towards the solution may be able to attract barium ions towards it, which might lead to less disruption of the crystal growth process than having a non-polar, non-ionic benzene ring directed toward the solution as in the case of isophthalic acid present.

\section{SUMMARY}

It has been shown that the different benzoic acids have variable impacts on the de-supersaturation rate or eventual morphology of particles obtained after precipitation of barite and calcite in their presence. The unusually high impact of isophthalic acid appears to be due to the spacing of the 1,3- motif $(\sim 5.3$ $\AA$ ), which coincides with the sulfate spacing on barite and the carbonate spacing on calcite. The same 1,3- motif in trimesic acid does not result in a similarly large impact on precipitation however. This seems to be due to the trimesic acid interacting with the crystal surface through a different mode of adsorption (ie orthogonal versus planar or hydrophilic versus hydrophobic residue in solution).

Generally, the more carboxylic acid groups on the inhibitor molecule, and the greater the extent of deprotonation, the greater the inhibitory effect of the benzoic acid. Mellitic acid, the most potent 
inhibitor of barite precipitation, was also found to have the most dramatic impact on the morphology of barite and calcite particles. For calcite, the presence of mellitic acid caused almost spherical aggregates of calcite rhombs to form while for barite, nanoparticles of barium sulfate formed spherical aggregates. The primary nanoparticle size in this case was found to be $\sim 20-50 \mathrm{~nm}$ in diameter.

Additionally, humic acid has been shown at ambient $\mathrm{pH}$ conditions to be a reasonably good barite inhibitor. The observed morphology changes suggest that this inhibition is not due to any complexation reaction but is the result of direct interaction with the surface (the (001) and (210) surfaces in particular). Also, the different behaviour of humic acid on both the precipitation kinetics and the morphology of the resulting barite casts some doubt on the validity of using benzoic acids as models for dissolved humic matter. On a more positive note, as environmental factors become ever more important, and the phase-out of phosphonate inhibitors appears inevitable, natural humic acid derivatives could be considered as alternatives.

ACKNOWLEDGMENT. F. Jones gratefully acknowledges that this research has been supported under the Australian Government's Cooperative Research Centre (CRC) Program, through the AJ Parker

CRC for Integrated Hydrometallurgy Solutions. We would also like to thank John Murphy of UWA's Centre for Microscopy and Microanalysis for preparing the ultramicrotomed samples.

\section{REFERENCES.}

1. K. S. Sorbie and E. J. Mackay, J. Petroleum Sci. Eng., 27 (2000) 85-106.

2. W. J. Benton, I. R. Collins, I. M. Grimsey, G. M. Parkinson, and S. A. Rodger, J. Chem. Soc. Faraday Disc., 95 (1993) 281-297.

3. P. J. Breen, H. H. Downs and B. N. Diel, Spec. Publ. - R. Soc. Chem., 97 (1991) 186-98.

4. H.-C. Schwarzer, W. Peukert, Chem. Eng. Technol., 25(6) (2002) 657-661. 
5. E. Lefebvre \& B. Legube, Water Research, 27(3) (1993) 433-447.

6. E. C. Yost, M. I. Tejedor-Tejedor, M. A. Anderson, M.A., Environ.Sci. Technol., 24 (1990) 822-828.

7. M. V. Biber, W. Stumm, Environ. Sci. Technol., 28 (1994) 763-768.

8. G. Cathalifaud, J. Ayele, M. Mazet, Water Research, 31(4) (1997) 689-698.

9. P.-C. Maria, J.-F. Gal, L. Massi, P. Burk, J. Tammiku-Taul, S. Tamp, Rapid Commun. Mass Spectrom., 19 (2005) 568-573

10. F. C. Meldrum, Int. Materials Rev., 48(3) (2003) 187-224.

11. H. Cölfen, Current Opinion in Colloid \& Interface Sci., 8(1) (2003) 23-31.

12. F. Jones, A. L. Rohl, M. I. Ogden, G. M. Parkinson, Materials Forum, 25 (2001) 116-135.

13. G. M. Graham, L. S. Boak, K. S. Sorbie, International Symposium on Oilfield Chemistry, Society of Petroleum Engineers, USA. 1997 SPE37273.

14. S. N. Black, L. A. Bromley, D. Cottler, R. J. Davey, B. Dobbs and J. E. Rout, J. Chem. Soc. Faraday Trans., 87(20) (1991) 3409-3414.

15. I. Weissbuch, L. Leiserowitz, M. Lahav in Crystallization Technology Handbook, A. Mersmann (eds), 1995, Marcel Dekker Inc., New York, Chap 6, 401-57.

16. S. He, J. E. Oddo, M. B. Thomson, Appl. Geochem., 9 (1994) 561-567.

17. F. Jones, M. Mocerino, M. I. Ogden, A. Oliveira and G. M. Parkinson, Cryst Growth \& Design, 5(6) (2005) 2336-2343.

18. F. Jones, J. Clegg, A. Oliveira, A. L. Rohl, M. I. Ogden, G. M. Parkinson, A. M. Fogg, M. M. Reyhani, CrystEngComm, 40 (2001) 1-3.

19. F. Jones, A. Oliveira, A. L. Rohl, M. I. Ogden, G. M. Parkinson, and M. M. Reyhani, Journal of Crystal Growth, 237-239 (2002) 424-429. 
20. F. Jones, A. Stanley, A. Oliveira, A. L. Rohl, M. M. Reyhani, G. M. Parkinson, M. I. Ogden, J. Crystal Growth, 249 (2003) $584-593$.

21. F. Jones, A. Oliveira, G. M. Parkinson, A. L. Rohl, A. Stanley, T. Upson, J. Crystal Growth, 262 (2004) 572-580.

22. L. Qi, H. Cölfen and M. Antonietti, Angew. Chemie Int. Ed., 39(3) (2000), 604-607.

23. F. Jones, W. R. Richmond, A. L. Rohl (2006) in press J. Phys. Chem., March issue

24. a) E. P. Serjeant, B. Dempsey, Ionization Constants of Organic Acids in Aqueous Solution, Pergamon, Oxford, 1979. b) S. Maji, K. Sundararajan, K. S. Viswanathan, Spectrochim. Acta A., 59 (2003) 455-461.

25. These structures were obtained from the Cambridge Crystallographic Database -

i) calcium phthalate monohydrate: a) M. P. Gupta, R. P. Sinha, Cryst. Struct. Commun., 4 (1975) 207 b) W. Schuckmann, H. Fuess, J. W. Bats, Acta Crystallogr. Sect. B, 34 (1978) 3754

ii) catena-(pentakis $\left(\left(\mu_{4}\right.\right.$-isophthalato)-nona-aqua-penta-calcium octahydrate): S. H. Dale, M. R. J. Elsegood, Acta Crystallogr. Sect. C, 59, (2003) m540

iii) catena- $\left(\left(\mu_{3}\right.\right.$-Terephthalato)-( $\mu_{2}$-aqua)-diaqua-calcium(ii)): a) T. Matsuzaki, Y. Iitaka, Acta Crystallogr. Sect. B, 28 (1972) 1977 b) R. H. Groeneman, J. L. Atwood, Crystal Engineering, 2 (1999) 241 c) S. H. Dale, M. R. J. Elsegood, Acta Crystallogr. Sect. E, 59, (2003) m586

iv) catena-(bis $\left(\left(\mu_{3}\right.\right.$-Benzene-1,3,5-tricarboxylato)-( $\mu_{2}$-aqua $\left.)\right)$-deca-aqua-tricalcium : Y.-Y. Yang, Z.-Q. Huang, L. Szeto, W.-T. Wong, Appl. Organomet. Chem., 18 (2004) 97.

v) catena-(Hexa-aqua( $\mu_{6}$-phenyl-1,2,4,5-tetracarboxylato)-dicalcium) : C. Robl, Z. Naturforsch. B: Chem. Sci., 43 (1988) 993. 
vi) Di-calcium dihydrogen mellitate nonahydrate: V. A. Uchtman, R. J. Jandacek, Inorg. Chem., 19 (1980) 350.

26. A. L. Rohl, D. H. Gay, R. J. Davey, C. R. A. Catlow, J. Am. Chem. Soc., 118 (1996) 642-648.

27. M. A. Nygren, D. H. Gay, C. R. A. Catlow, M. P. Wilson, A. L. Rohl, J. Chem. Soc. Faraday Trans., 94 (1998) 3685-3693.

28. T. Nagayasu, C. Yoshioka, K. Imamura, K. Nakanishi, J. Colloid and Interface Sci., 279 (2004) 296-306.

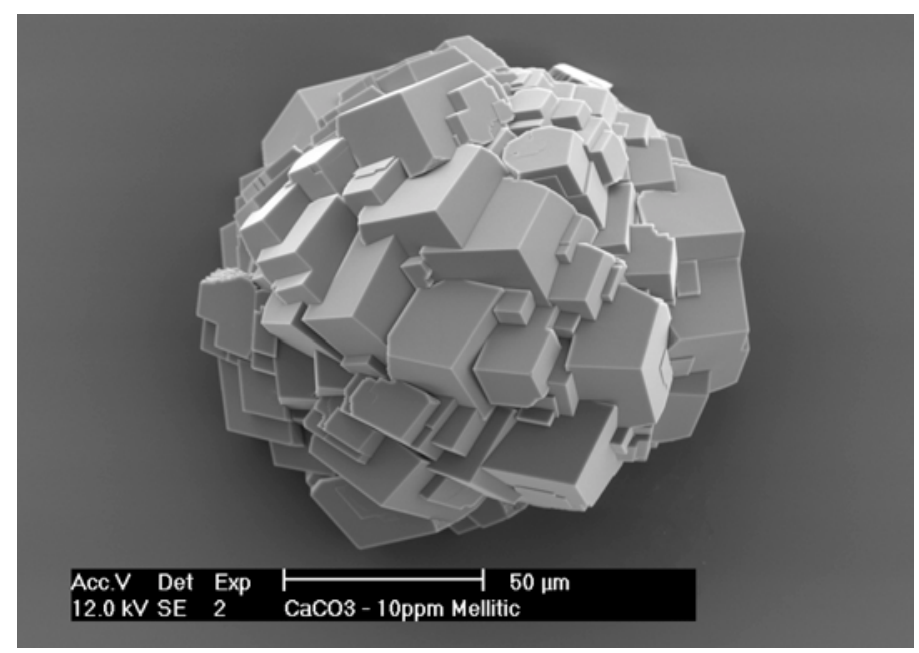

SYNOPSIS TOC.

Benzoic acids with varying number of carboxylate groups were found to affect barite and calcite precipitation, mellitic acid was found to be a particularly potent inhibitor. 


\section{SUPPORTING INFORMATION.}

Figure Supp 1 Scanning electron micrographs of calcite crystallised in the presence of $10 \mathrm{ppm}$ of (a) phthalic acid, (b) isophthalic acid and (c) terephthalic acid.

(a)

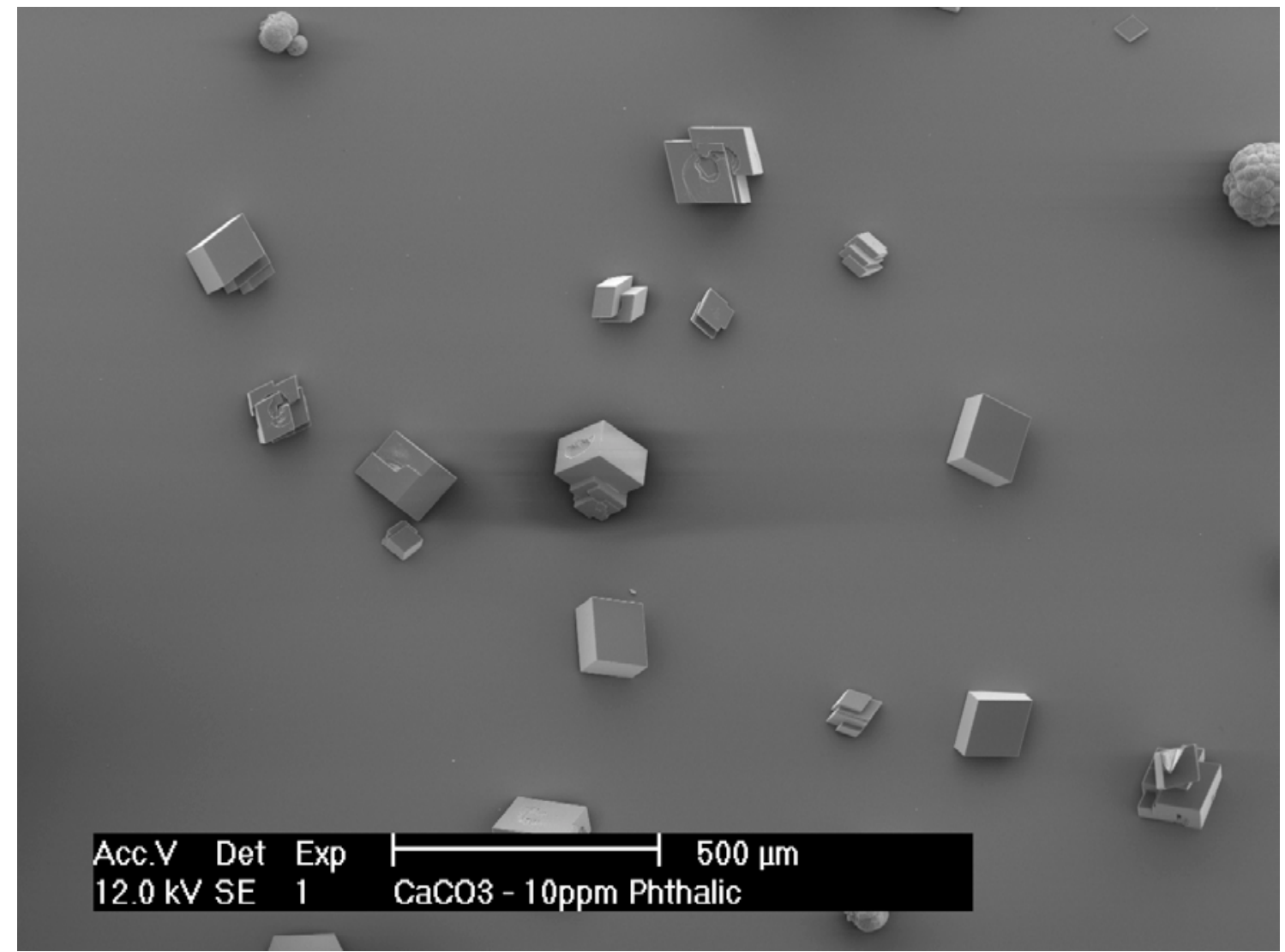

(b) 


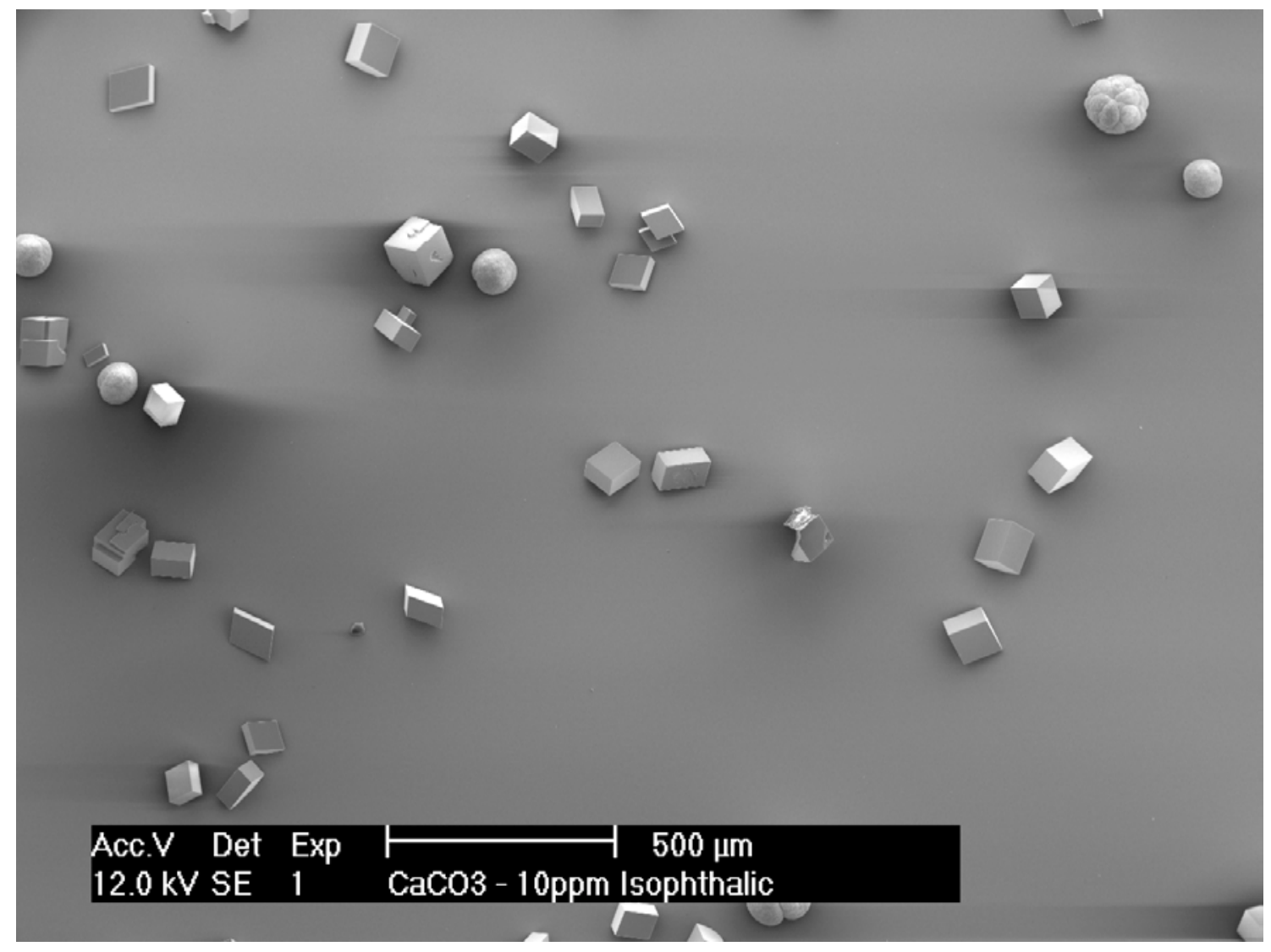

(c)

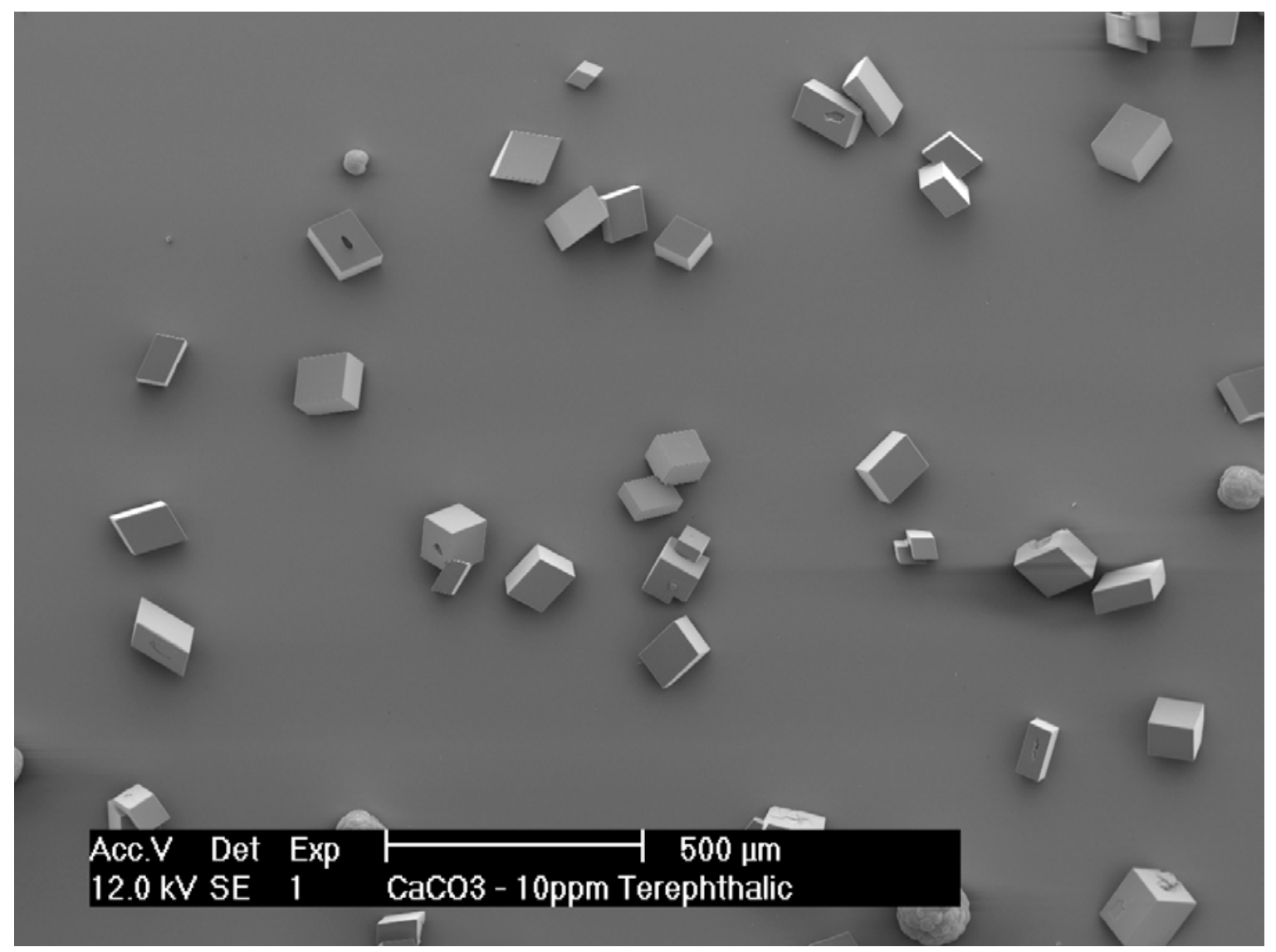


Figure Supp2. XRD patterns

A. For barium sulfate (control)

Barite (Control)

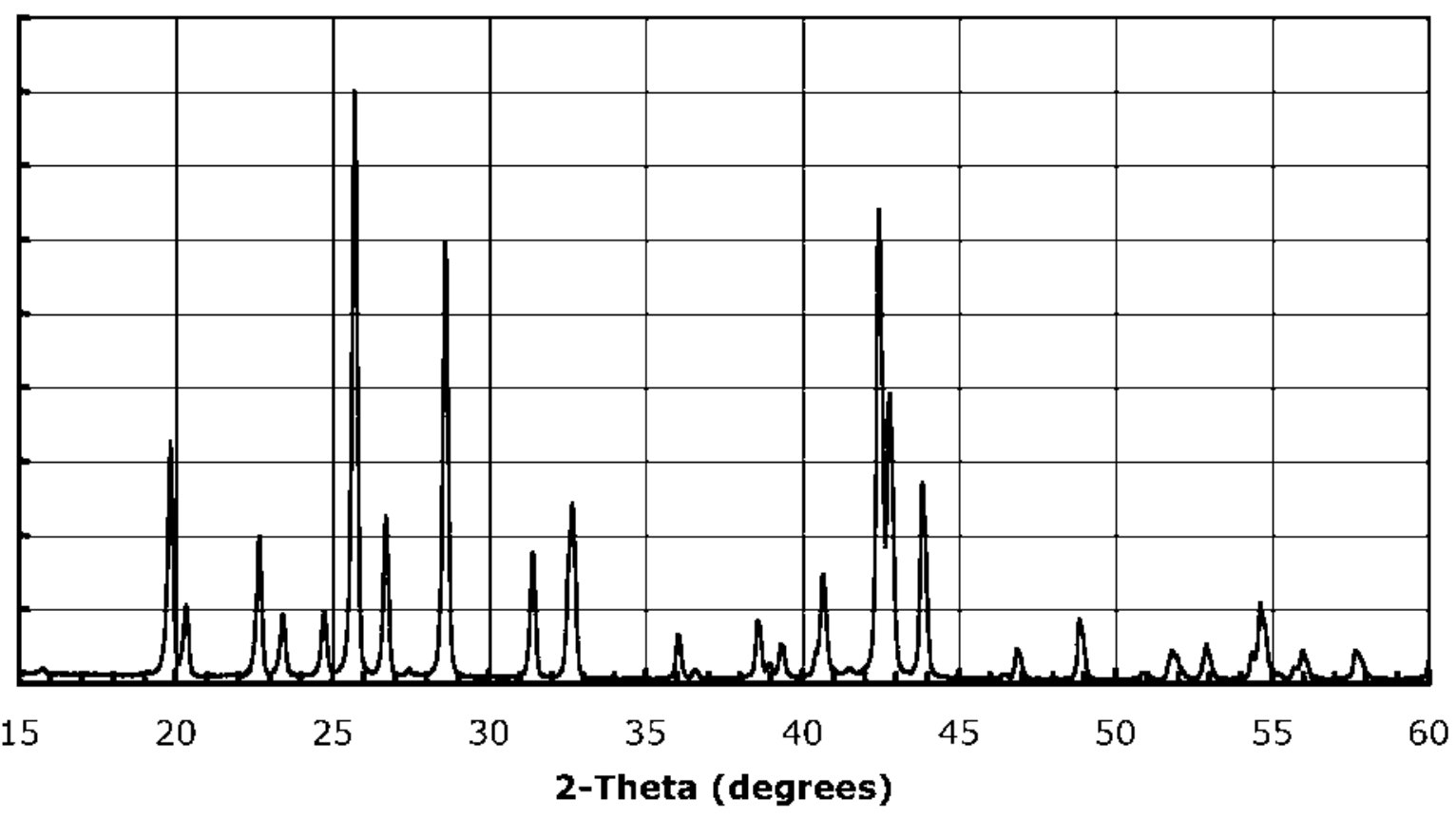

B. XRD pattern for barium sulfate in the presence of trimesic acid (10ppm)

Barite (Trimesic)

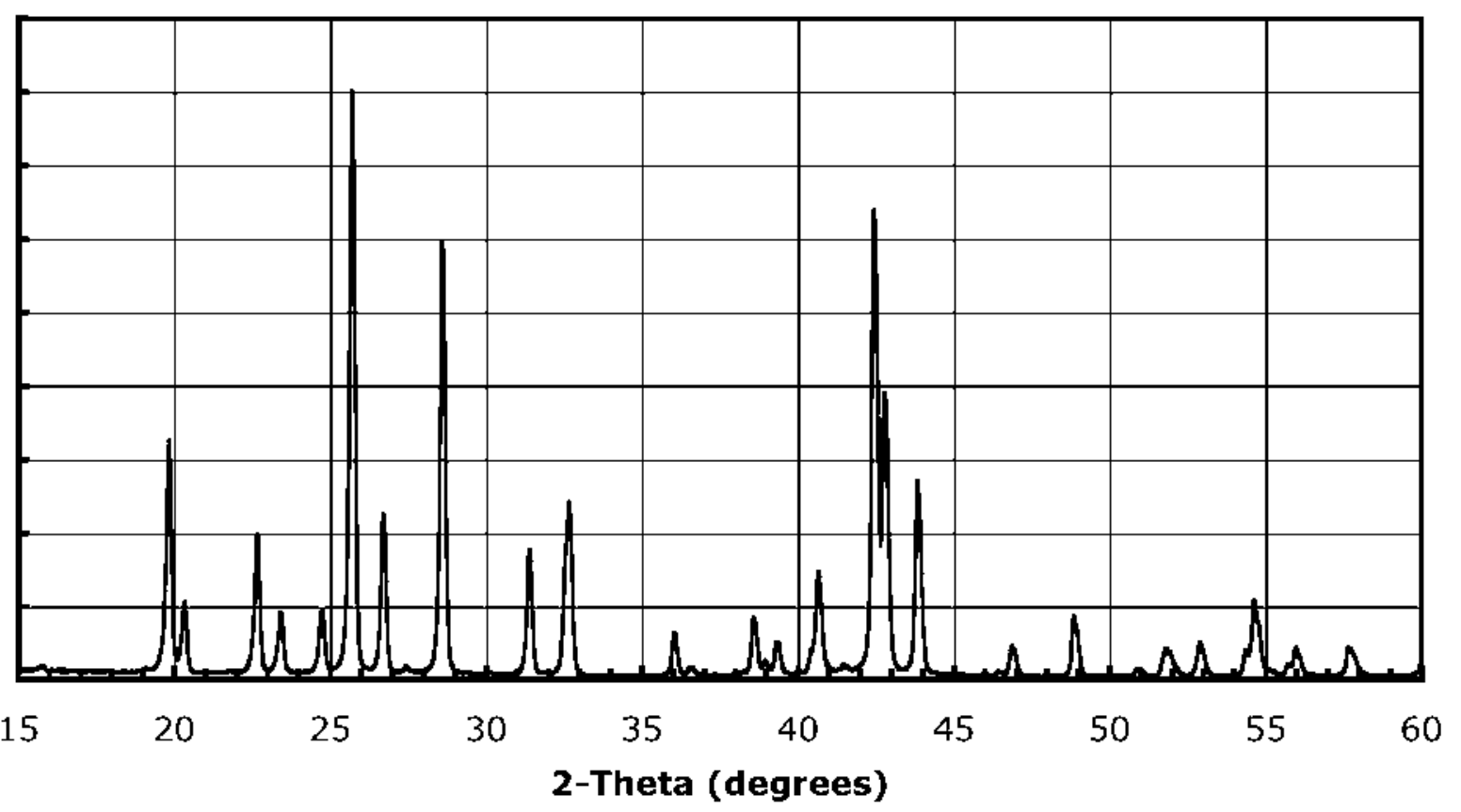


C. XRD pattern of barium sulfate in the presence of mellitic acid (10ppm)

Barite (Mellitic)

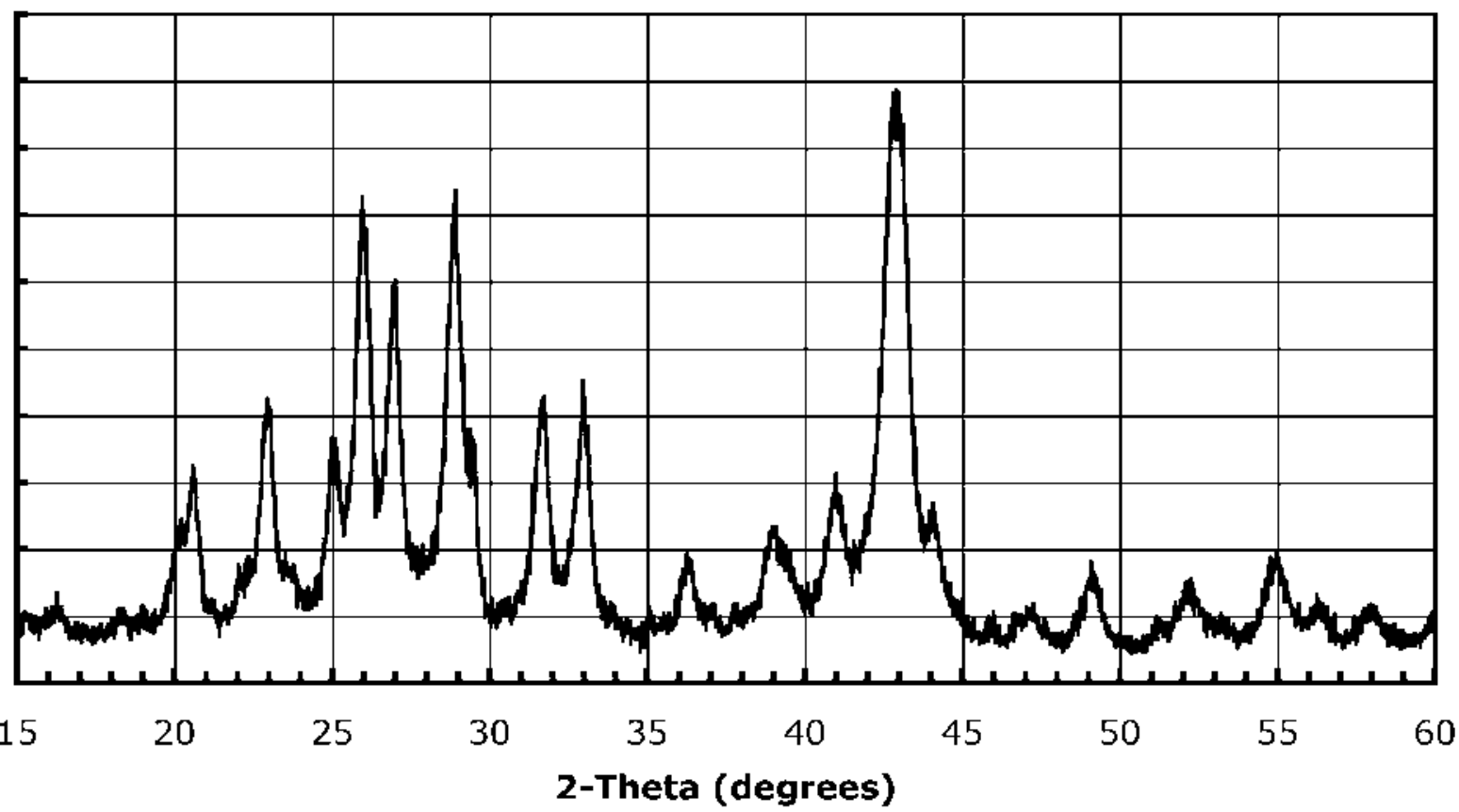

D. XRD pattern of barium sulfate in the presence of humic acid (10ppm)

Barite (Humic)

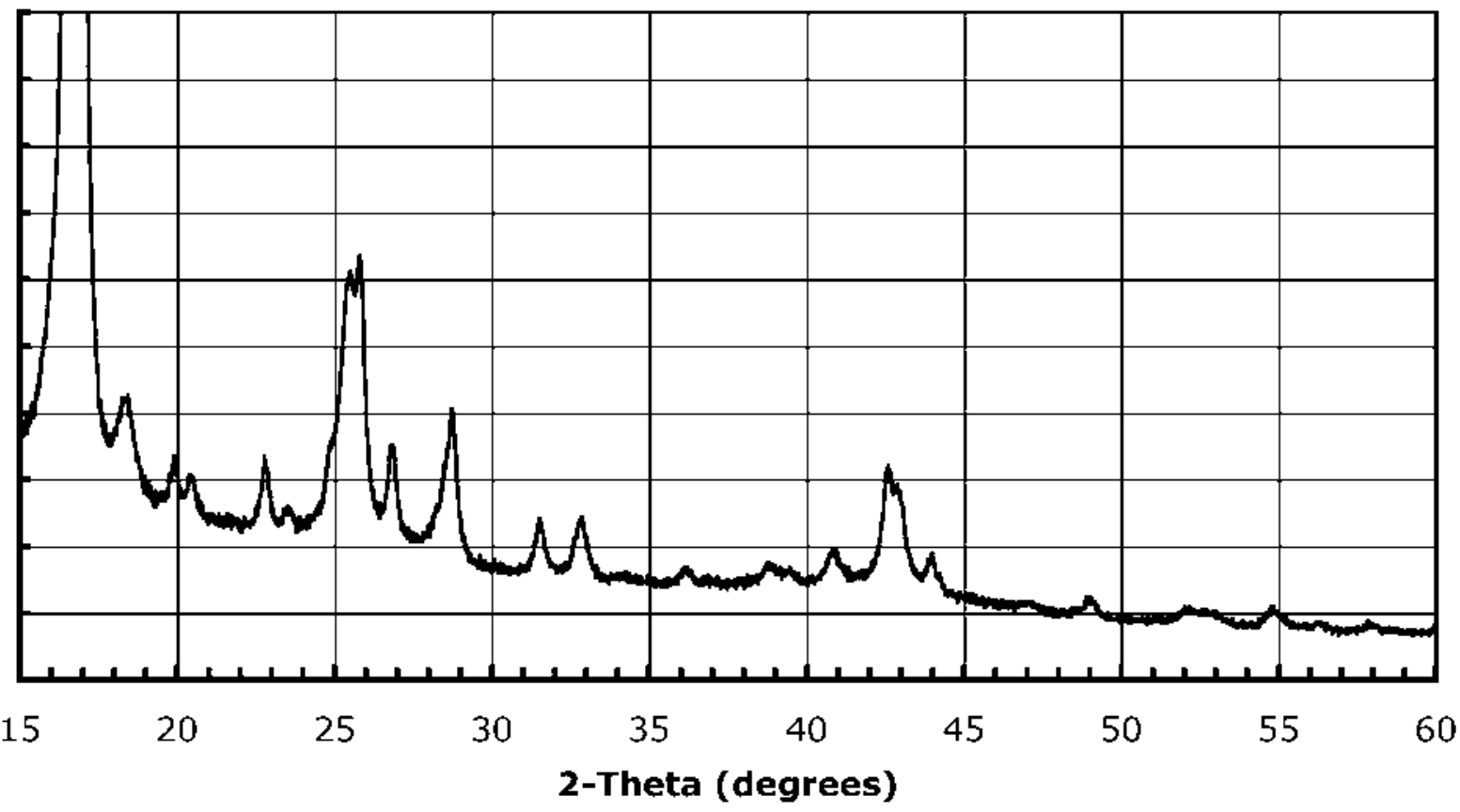


Table A1: Crystallite sizes calculated from linewidths of 211, 112 and 020 reflections using the Scherrer equation.

\begin{tabular}{|c|c|c|c|c|}
\hline Sample & Reflection & Angle 2q & FWHM & $\begin{array}{c}\text { crystallite } \\
\text { size }(\AA)\end{array}$ \\
\hline
\end{tabular}

$\begin{array}{lllll}\text { Mellitic } & 211 & 28.92 & 0.642 & 192.98 \\ & 112 & 31.68 & 0.564 & 237.98 \\ & 020 & 32.96 & 0.573 & 235.95\end{array}$

$\begin{array}{lllll}\text { Humic } & 211 & 28.72 & 0.534 & 250.06 \\ & 112 & 31.52 & 0.424 & 369.50 \\ & 020 & 34.84 & 0.514 & 282.81\end{array}$

$\begin{array}{lllll}\text { Trimesic } & 211 & 28.6 & 0.188 & 5613.4\end{array}$ 


$\begin{array}{lrrr}112 & 31.4 & 0.181 & 10209.6 \\ 020 & 32.66 & 0.281 & 864.4\end{array}$

$\begin{array}{rrrrr}\text { Control } & 211 & 28.58 & 0.184 & 7465.8 \\ & 112 & 31.38 & 0.191 & 4866.7 \\ & 020 & 32.64 & 0.23 & 1622.7\end{array}$


Possible Cover Art
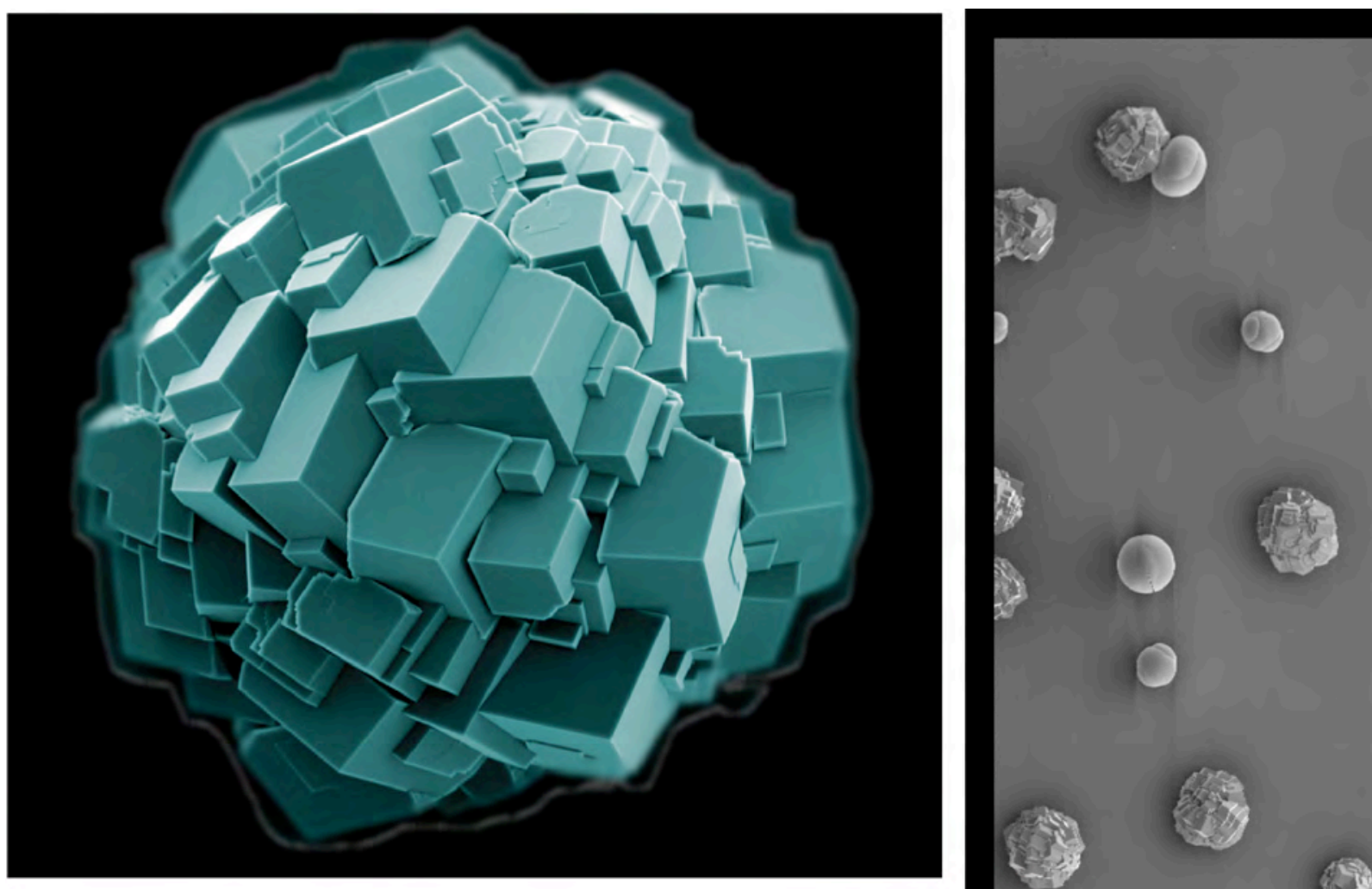

(2)

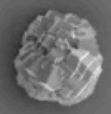

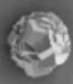

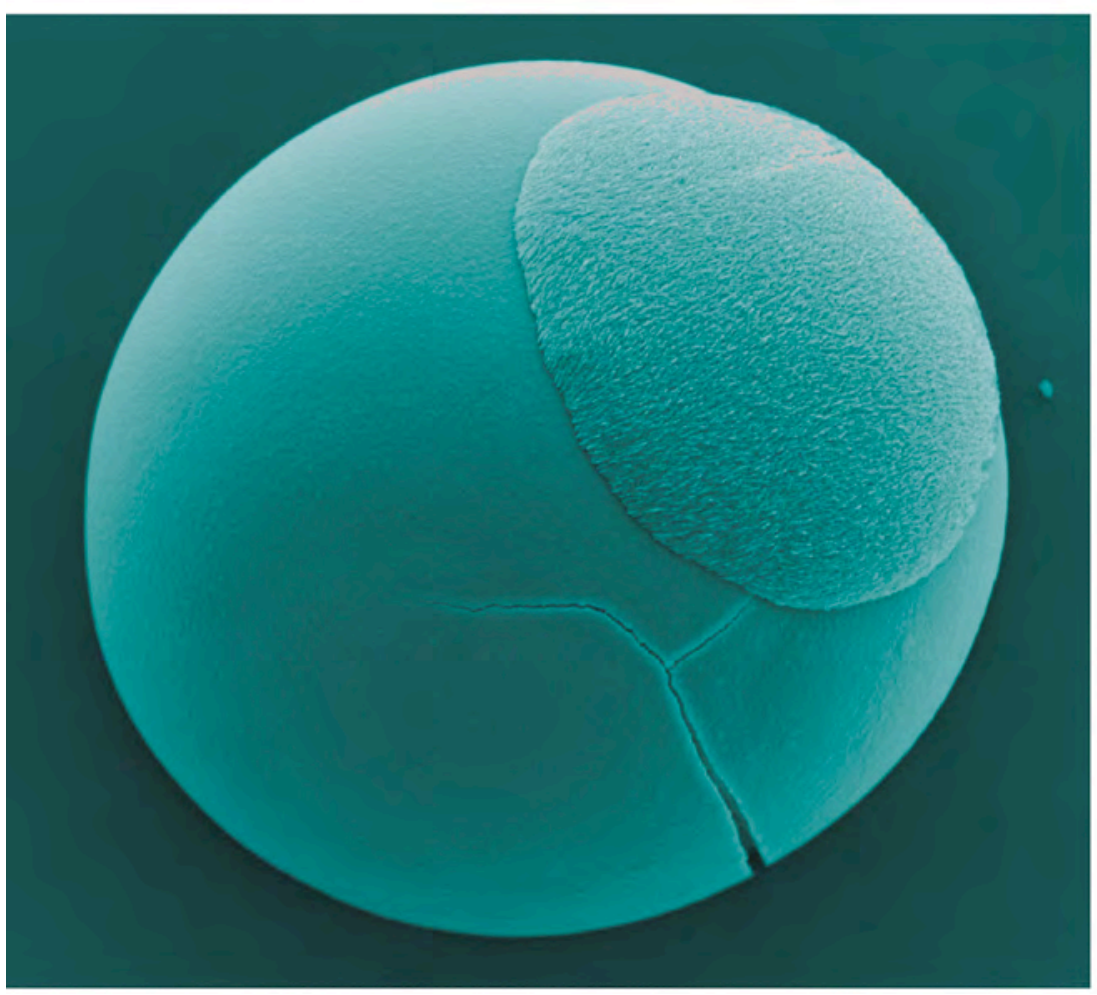

168

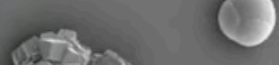

$Q$

8078

and

살

0

0 